\title{
Epidemiology, species distribution, antifungal susceptibility and mortality risk factors of candidemia among critically ill patients: a retrospective study from 2011 to 2017 in a teaching hospital in China
}

\author{
Zengli Xiao, Qi Wang, Fengxue Zhu and Youzhong $A n^{*}$
}

\begin{abstract}
Background: Candidemia is still a common life-threatening disease and causes significant morbidity and mortality, especially in critically ill patients. We conducted this study to analyze the epidemiology, clinical characteristics, species distribution, antifungal susceptibility and mortality risk factors of candidemia in an intensive care unit.

Methods: We retrospectively analyzed patients with candidemia in the intensive care unit of our hospital from 2011 to 2017. The clinical characteristics, including clinical and laboratory data, antibiotic therapies, underlying conditions, and invasive procedures and outcomes, were analyzed. We also performed a logistic regression analysis to identify the independent risk factors for mortality.

Results: In this six-year retrospective study, we identified 82 patients with candidemia. The median age of the patients was 76 years (range, 26 years to 91 years), and 50 of the patients (61\%) were male. Candida albicans was the most common fungal species (38/82, 46.3\%), followed by Candida parapsilosis (16/82, 19.5\%), Candida glabrata (13/82, 15.9\%), and Candida tropicalis (12/82, 14.6\%). Most isolates were susceptible to the antifungal agents. The all-cause mortality rate was $51.2 \%$. In binary logistic regression analysis, the worst Glasgow coma score (GCS), $\mathrm{PaO}_{2} / \mathrm{FiO}_{2}$ ratio (P/F ratio), and mean arterial pressure (MAP) within three days after admission were independent risk factors for mortality.

Conclusions: Candida albicans was the most frequently isolated fungal species. Most isolates were susceptible to the antifungal agents. The worst GCS score, P/F ratio, and MAP within three days after admission were independent risk factors for mortality due to candidemia in critically ill patients.
\end{abstract}

Keywords: Candidemia, Species distribution, Antifungal susceptibility, Risk factors

\section{Background}

Invasive candidiasis (IC) has become a substantial threat to public health. IC affects more than 250,000 people every year and is associated with a mortality rate exceeding $70 \%[1-3]$.

Traditionally, IC has been associated with immunocompromised states, chronic inflammatory diseases and chronic immunosuppressive conditions. The use of

\footnotetext{
* Correspondence: anyouzhong1234@126.com; bjicu@163.com Peking University People's Hospital, No. 11 Xizhimen South Street, Xicheng District, Beijing 100044, People's Republic of China
}

broad-spectrum antibiotics, any pre-existing cause of immunosuppression, recent surgery and indwelling central venous catheters $(\mathrm{CVC})$, particularly those for total parenteral nutrition, are all associated with IC [4, 5]. Therefore, the number of patients at risk of fungal infection is rising in intensive care units (ICUs), and as the third most common cause of infection in the ICU worldwide, accounting for $17 \%$ of infections, it has become a growing concern for doctors [6-8].

Thus far, more than 17 different Candida species have been identified as causative pathogens of bloodstream

(c) The Author(s). 2019 Open Access This article is distributed under the terms of the Creative Commons Attribution 4.0 International License (http://creativecommons.org/licenses/by/4.0/), which permits unrestricted use, distribution, and 
infections (BSIs), and Candida albicans is the dominant and most extensively studied pathogen $[9,10]$. However, the proportion of non-Candida albicans strains has increased rapidly in recent years [11]. In general, more than $90 \%$ of IC are caused by C. albicans, C. tropicalis, C. parapsilosis, C. glabrate and C. krusei [12, 13].

In the ICU, the treatment of IC remains a challenge. Systemic antifungal therapy is used in up to $7.5 \%$ of ICU patients, although two-thirds of these patients have no documented IC [14]. The current guidelines also recommend empiric antifungal treatment, although it often fails to confer any benefit on ICU patients $[15,16]$. Therefore, the availability of local epidemiological data could help improve antifungal stewardship.

The aim of this study was to describe the epidemiology, clinical characteristics, species distribution, antifungal susceptibility and mortality risk factors for of candidemia in an ICU in China. We believe that knowledge of IC epidemiology, including geographical differences, is an important guide to prescribing practices and health policies and thus has far-reaching clinical implications [17].

\section{Methods}

\section{Patients and setting}

From March 2011 to September 2017, all patients with candidemia reported by the microbiological department of the ICU of Peking University People's Hospital in China were retrospectively identified and analyzed. There are 41 beds in this general ICU. The medical records of all patients due to Candida infection were reviewed, and the following information was collected: age, sex, patient source (medical/surgical ward), underlying conditions (diabetes, hypertension, chronic obstructive pulmonary disease, chronic cardiac disease, chronic liver disease, solid tumor, hematological malignancy, chronic renal dysfunction, surgery within 1 month), the worst GCS score within 3 days after admission to the ICU, previous treatment (antifungal treatment, steroid therapy, antibiotic therapy), the worst laboratory data within 3 days after admission to the ICU (P/F ratio, hemoglobin level, neutrophil count, white blood cell count, temperature, serum total protein level, serum albumin level, MAP), previous invasive procedures (central venous catheter, urinary tract catheter, total parenteral nutrition), and the worst Sequential Organ Failure Assessment (SOFA) score within 3 days after admission to the ICU (length of ICU, length of hospital stay, and duration of mechanical ventilation).

\section{Definitions}

We defined candidemia as the isolation of Candida species from at least one blood culture in patients with symptoms or signs of a systemic infection. Anemia was defined as a hemoglobin level $<70 \mathrm{~g} / \mathrm{l}$. Neutropenia was defined as an absolute neutrophil count $<1.5^{*} 10^{9} / \mathrm{l}$. Hypoproteinemia was defined as a total protein level $<60 \mathrm{~g} / \mathrm{dl}$ or serum albumin level $<25 \mathrm{~g} / \mathrm{dl}$. Empirical antifungal therapy was defined as the administration of antifungals in patients with refractory pyrexia and other risk factors for IC before the results of antifungal sensitivity testing were obtained.

\section{Microbiology and antifungal susceptibility testing}

Isolates were collected from blood cultures using the ALERT 3D automated system (bioMérieux, Marcy l'Etoile, France) and were identified by the Vitek 2 automated system (bioMérieux, Marcy l'Etoile, France). Antifungal susceptibility testing was performed using the ATB FUNGUS 3 strip (bioMérieux, Marcy l'Etoile, France) in accordance with the manufacturer's instructions. Five antifungal drugs with different concentrations, namely, 5-flucytosine, amphotericin B, fluconazole, itraconazole and voriconazole, were tested. After incubation at $35^{\circ} \mathrm{C}$ for $24 \mathrm{~h}$, the strips were read visually to determine the scores. The MICs were interpreted according to species-specific Clinical \& Laboratory Standards (CLSI) M27-A3 breakpoints. C. krusei ATCC 6258 and C. parapsilosis ATCC 2019 were used as quality controls [18].

\section{Statistical analysis}

Data were analyzed with SPSS software version 21.0. The count data were described by case number (n), and the difference between groups was tested by the Chi-square test or Fisher's exact test. The Shapiro-Wilk normality test showed that the measurement data did not conform to a normal distribution $(p<0.05)$. Therefore, the measurement data in this study were described by P50 (P25,P75), and a nonparametric rank sum test was used for intergroup comparison. Factors with a $p<0.05$ in univariate tests were analyzed with a binary logistic regression model to identify the independent risk factors. The difference was statistically significant when $p<0.05$.

\section{Results}

Patient characteristics and distribution of Candida species Eighty-two patients with candidemia were identified over a 6-year period. The median age of the patients was 76 years (range, 26 years to 91 years), and 50 patients (61\%) were male. Approximately $65.9 \%$ of the patients came from the surgical ward. Surgery within 1 month (58.5\%), hypertension (43.9\%), and solid tumors (36.6\%) were the most common underlying conditions, followed by diabetes (32.9\%), chronic cardiac disease (22\%), chronic renal dysfunction (20.7\%), chronic liver disease (11\%), hematological malignancy (6.1\%), and chronic obstructive 
Table 1 Baseline characteristics of 82 patients diagnosed with IC in the ICU

\begin{tabular}{|c|c|c|c|c|c|}
\hline & \multirow{2}{*}{$\begin{array}{l}N(\%) \text { or } P_{50} \\
\left(P_{25}, P_{75}\right)\end{array}$} & \multicolumn{4}{|c|}{ Mortality status (all-cause) } \\
\hline & & Survived $(n=40)$ & Did not survive $(n=42)$ & Z/ $x^{2} /$ Fisher's exact test & $P$ \\
\hline Age (years) & $76.0(65.8,82.0)$ & $76.0(61.3,81.8)$ & $78.0(67.0,84.0)$ & $-0.673^{\#}$ & 0.501 \\
\hline Males & $50(61.0)$ & $26(65.0)$ & $24(57.1)$ & $0.532^{*}$ & 0.466 \\
\hline \multicolumn{6}{|l|}{ Hospital admission } \\
\hline Medical ward & $28(34.1)$ & $14(35.0)$ & $14(33.3)$ & \multirow[t]{2}{*}{$0.025^{*}$} & \multirow[t]{2}{*}{0.874} \\
\hline Surgical ward & $54(65.9)$ & $26(65.0)$ & $28(66.7)$ & & \\
\hline \multicolumn{6}{|l|}{ Underlying conditions } \\
\hline Diabetes & $27(32.9)$ & $12(30.0)$ & $15(35.7)$ & $0.303^{*}$ & 0.582 \\
\hline Hypertension & $36(43.9)$ & $14(35.0)$ & $22(52.4)$ & $2.513^{*}$ & 0.113 \\
\hline Chronic cardiac disease & $18(22.0)$ & $7(17.5)$ & $11(26.2)$ & $0.903^{*}$ & 0.342 \\
\hline Chronic liver disease & $9(11.0)$ & $5(12.5)$ & $4(9.5)$ & $0.006^{*}$ & 0.938 \\
\hline Solid tumor & $30(36.6)$ & $15(37.5)$ & $15(35.7)$ & $0.028^{*}$ & 0.867 \\
\hline COPD & $2(2.4)$ & $0(0.0)$ & $2(4.8)$ & $\Delta$ & 0.494 \\
\hline Hematological malignancy & $5(6.1)$ & $2(5.0)$ & $3(7.1)$ & $0.000^{*}$ & 1.000 \\
\hline Chronic renal dysfunction & $17(20.7)$ & $4(10.0)$ & $13(31.0)$ & $5.473^{*}$ & 0.019 \\
\hline Surgery & $48(58.5)$ & $25(62.5)$ & $23(54.8)$ & $0.505^{*}$ & 0.477 \\
\hline GCS score & $11.0(9.0,15.0)$ & $11.0(11.0,15.0)$ & $10.0(6.0,11.0)$ & $-4.225^{\#}$ & 0.000 \\
\hline \multicolumn{6}{|l|}{ Previous treatment } \\
\hline Antifungal treatment & $27(32.9)$ & $12(30.0)$ & $15(35.7)$ & $0.303^{*}$ & 0.582 \\
\hline Caspofungin & $22(26.8)$ & $11(27.5)$ & $11(26.2)$ & $0.018^{*}$ & 0.894 \\
\hline Fluconazole & $39(47.6)$ & $19(47.5)$ & $20(47.6)$ & $0.000^{*}$ & 0.991 \\
\hline Amphotericin B & $2(2.4)$ & $0(0.0)$ & $2(4.8)$ & $\Delta$ & 0.494 \\
\hline Voriconazole & $32(39.0)$ & $18(45.0)$ & $14(33.3)$ & $1.172^{*}$ & 0.279 \\
\hline Previous steroid therapy & $25(30.5)$ & $10(25.0)$ & $15(35.7)$ & $1.110^{*}$ & 0.292 \\
\hline Previous antibiotic therapy & $63(76.8)$ & $31(77.5)$ & $32(76.2)$ & $0.020^{*}$ & 0.888 \\
\hline \multicolumn{6}{|l|}{ Laboratory data } \\
\hline P/F ratio & $256.1(188.4,337.3)$ & $290.5(241.5,370.8)$ & $224.0(130.0,270.0)$ & $-3.553^{\#}$ & 0.000 \\
\hline Anemia $(\mathrm{HGB}<70 \mathrm{~g} / \mathrm{l})$ & $27(32.9)$ & $10(25.0)$ & $17(40.5)$ & $2.222^{*}$ & 0.136 \\
\hline Neutropenia (< 1 months) & $7(8.5)$ & $2(5.0)$ & $5(11.9)$ & $0.523^{*}$ & 0.470 \\
\hline$W B C>20^{*} 10^{9} / I$ & $26(31.7)$ & $11(27.5)$ & $15(35.7)$ & $0.638^{*}$ & 0.424 \\
\hline Temperature $>38^{\circ} \mathrm{C}$ & $68(82.9)$ & $31(77.5)$ & $37(88.1)$ & $1.624^{*}$ & 0.202 \\
\hline Hypoproteinemia & $81(98.8)$ & $39(97.5)$ & $42(100.0)$ & $\Delta$ & 0.488 \\
\hline MAP, mean (SD) & $76.7(66.5,90.0)$ & $85.5(73.3,94.5)$ & $68.0(57.0,78.3)$ & $-4.134^{\#}$ & 0.000 \\
\hline \multicolumn{6}{|l|}{ Previous invasive procedures } \\
\hline Central venous catheter & $13.0(5.5,27.0)$ & $13.0(6.0,25.5)$ & $14.0(4.5,29.5)$ & $-0.454^{\#}$ & 0.650 \\
\hline Urinary tract catheter & $13.0(5.0,27.0)$ & $12.5(5.0,24.0)$ & $17.0(5.5,35.5)$ & $-1.026^{\#}$ & 0.305 \\
\hline Total parenteral nutrition & $10.5(3.8,21.3)$ & $8.5(3.3,15.8)$ & $13.0(4.5,27)$ & $-1.023^{\#}$ & 0.307 \\
\hline Mechanical ventilation & $3.5(1.0,10.3)$ & $2.5(1.0,9.5)$ & $5.50(1.0,15.0)$ & $-1.514^{\#}$ & 0.130 \\
\hline SOFA score & $8.0(4.0,11.0)$ & $5.0(4.0,8.0)$ & $10.0(8.5,14.0)$ & $-4.628^{\#}$ & 0.000 \\
\hline \multicolumn{6}{|l|}{ Outcome (days) } \\
\hline ICU length of stay & $16.0(4.8,51.8)$ & $16.0(5.3,36.3)$ & $14.5(3.0,66.0)$ & $-0.223^{\#}$ & 0.823 \\
\hline Hospital length of stay & $45.0(27.8,81.3)$ & $40.0(28.0,98.0)$ & $49.0(26.5,81.0)$ & $-0.014^{\#}$ & 0.989 \\
\hline Mechanical ventilation & $8.5(1.8,23.3)$ & $5.0(1.0,11.0)$ & $11.5(3.0,37.5)$ & $-2.461^{\#}$ & 0.014 \\
\hline
\end{tabular}

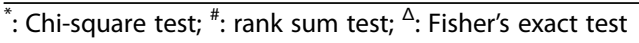
$\mathrm{P}_{50}\left(\mathrm{P}_{25}, \mathrm{P}_{75}\right)$ : the quartile summary is viewed as $\mathrm{P} 25, \mathrm{P} 50$, and $\mathrm{P} 75$. For $\mathrm{P} 50$, there is a $50 \%$ chance that the mean power production will not be reached at any given time 
pulmonary disease (COPD) (2.4\%). The median GCS score of these patients was 11. In total, 27 (32.9\%) patients had received previous antifungal treatment. Fluconazole was the most frequently used empirical antifungal treatment $(40 / 64,62.5 \%)$. The patients' laboratory data and previous invasive procedures are also shown in Table 1.

\section{Distribution of Candida spp. causing BSIs}

Candida albicans was by far the most prevalent fungal species (46.3\%), followed by Candida parapsilosis (19.5\%), Candida glabrata (15.9\%), Candida tropicalis (14.6\%), Candida dubliniensis (1.2\%), Candida guilliermondii (1.2\%), and Candia spp. (1.2\%) (Fig. 1).

\section{Susceptibilities of the isolates}

The in vitro antifungal susceptibility of the isolated Candida species is presented in Fig. 2. Overall, most isolates were susceptible to the antifungals. $C$. albicans, C. tropicalis, and C. parasilosis were highly susceptible to all antifungal agents, whereas the other Candida species had low levels of susceptibility to fluconazole and itraconazole. Itraconazole had the highest drug resistance rate, while no species showed resistance to amphotericin $B$.

\section{Outcomes and risk factors for mortality}

The all-cause in-hospital mortality rate of the 82 patients was $42 / 82$ (51.2\%). In univariate analyses, increased mortality was associated with chronic renal dysfunction, GCS score, P/F ratio, MAP, and SOFA score, as shown in Table 1 . The median ICU length of stay and hospital length of stay were 16 days and 45 days respectively. The median duration of mechanical ventilation was 8.5 days and the survived group was significant less than died group (Table 1). In binary logistic regression analysis, the worst value of GCS score, P/F ratio, MAP within three days after admission were independent risk factors for mortality (Table 2).

\section{Discussion}

We report a 6-year retrospective study of candidemia at the Peking University People's Hospital, a teaching hospital in China. We not only focused on the main epidemiological characteristics, such as risk factors and antifungal agent use, but we also obtained a complete overview of candidemia, including Candida species identification, antifungal resistance determination and patient outcome analysis.

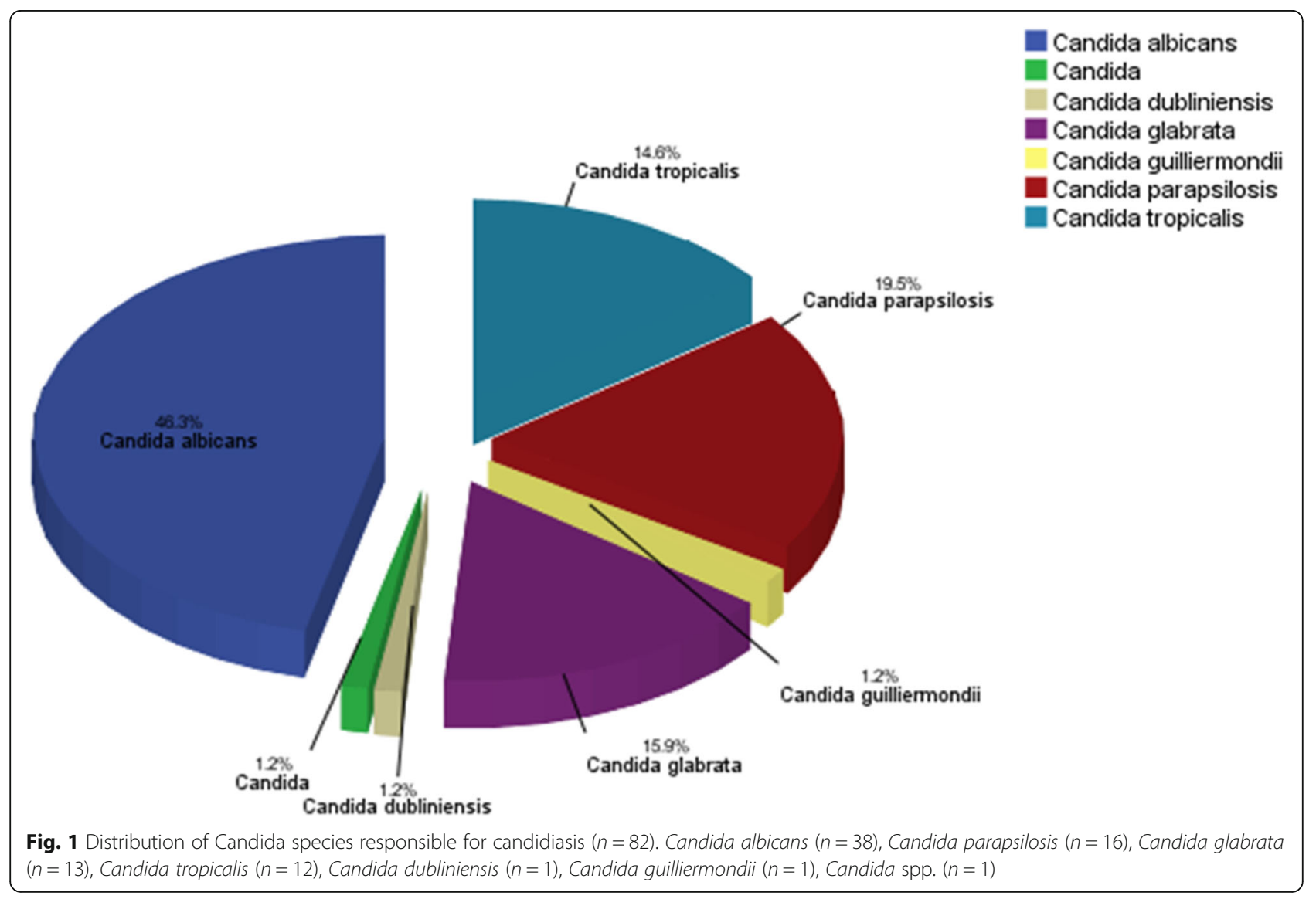




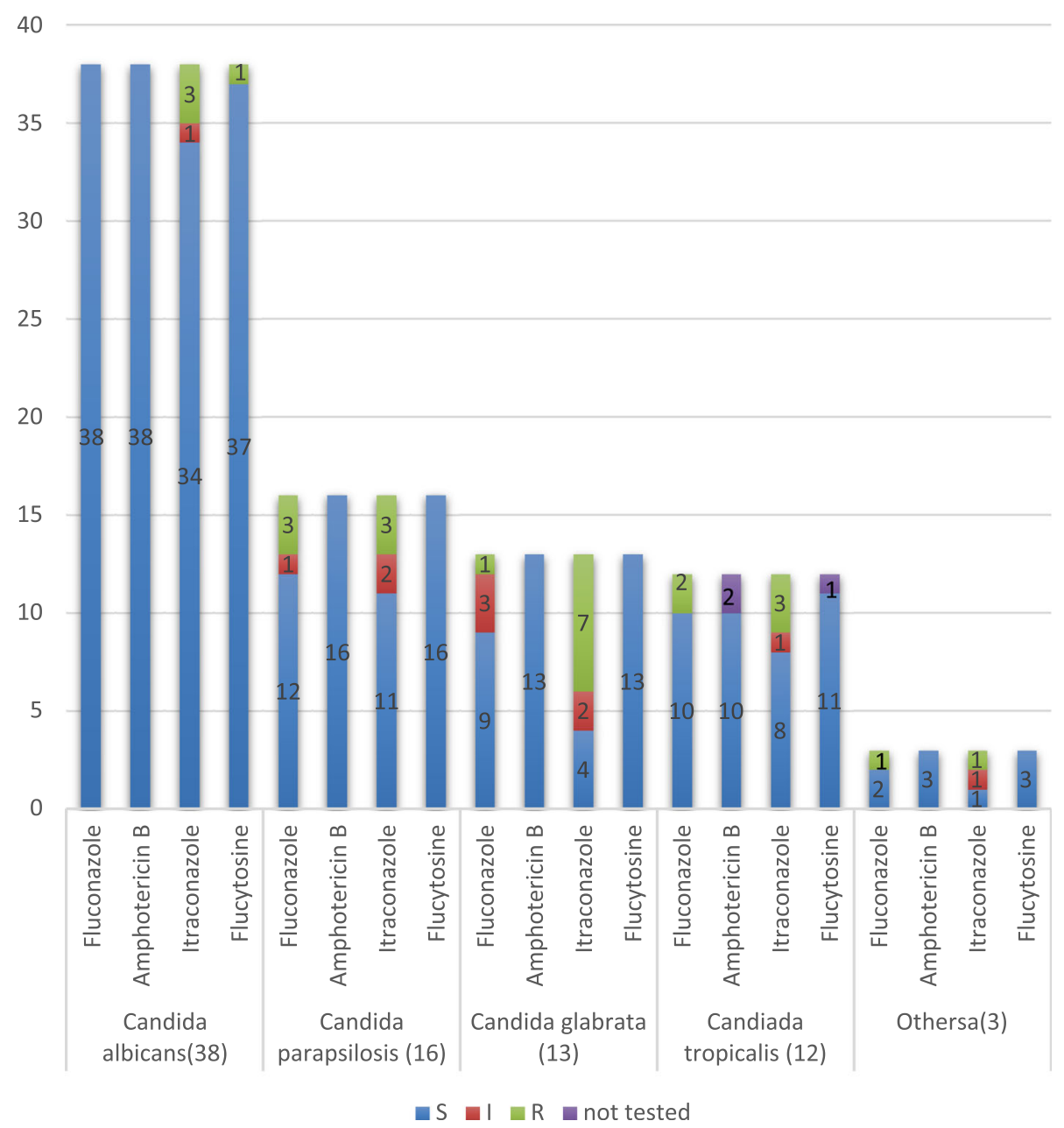

Fig. 2 In vitro susceptibility data for the Candida spp. ${ }^{a}$ Others include Candida dubliniensis $(n=1)$, Candida guilliermondii $(n=1)$, and Candia $(n=1)$. $\mathrm{S}=$ susceptible; $\mathbf{I}=$ intermediate; $\mathrm{R}$ = resistant

The mean age of patients in our study was older than the mean ages in previous studies, possibly because we mainly focused on critically ill patients; critically ill patients are often older than other patients $[2,19,20]$. Similar to other studies, C. albicans was the most common species causing candidemia, followed by C. parapsilosis, C. glabrata, and C. tropicalis [21-25]. This may be due to increasing numbers

Table 2 Risk factors for mortality

\begin{tabular}{llllll}
\hline & B & Wald & OR & Cl & $P$ \\
\hline Chronic renal dysfunction & 1.458 & 2.664 & 4.299 & $0.746-24.772$ & 0.103 \\
GCS score & -0.256 & 4.408 & 0.774 & $0.610-0.983$ & 0.036 \\
P/F ratio & -0.006 & 4.862 & 0.994 & $0.988-0.999$ & 0.027 \\
MAP & -0.046 & 5.220 & 0.955 & $0.919-0.994$ & 0.022 \\
SOFA score & 0.114 & 1.431 & 1.121 & $0.930-1.352$ & 0.232
\end{tabular}

B:coefficient estimates; Wald: Chi-square value; OR: Odds ratio; $\mathrm{Cl}$;Confidence interval of surgeries, the aging of the population, and the increasing use of antifungal agents.

Susceptibility testing for antifungal drugs was performed for all isolates of Candida species. In our study, fluconazole was active against $C$. albicans, but a trend towards increased resistance or the emergence of naturally resistant species was observed among other Candida spp., implying that fluconazole could be used in patients with Candida albicans as a first-line agent [26]. For patients infected with other Candida spp., fluconazole should be used according to the results of the susceptibility test. Amphotericin B demonstrated excellent activity against all Candida species. Resistance to itraconazole was relatively more common in all Candida species, which was consistent with the findings of other studies [27]. These findings should be taken into consideration when establishing antifungal treatment strategies.

Invasive Candida infection in the ICU is an increasing concern due to its high associated mortality rate and 
resource consumption. According to previous studies, invasive Candida infection is associated with mortality rates of $35-80 \%$ in the ICU [28-31]. The all-cause mortality of patients with candidemia in our study was $51.2 \%$, which is within the range of previously reported mortality rates [32,33]. The mean time between diagnosis and death was 16.7 days. The ICU length of stay and hospital length of stay for candidemia patients were much longer than those for general ICU patients [34].

In univariate analyses, increased mortality was associated with chronic renal dysfunction, GCS score, P/F ratio, MAP, and SOFA score, as shown in Table 1. The median ICU length of stay and hospital length of stay were 16 days and 45 days, respectively. The median duration of mechanical ventilation was 8.5 days, and the duration was significantly shorter in the surviving group was significantly less than the nonsurviving group (Table 1). In binary logistic regression analysis, the worst GCS score, P/F ratio, and MAP within 3 days after admission were independent risk factors for mortality.

In our study, most of the patients had long durations of central venous catheterization, urinary tract catheterization, and mechanical ventilation, which have been shown to be responsible for fungal infections $[10,35,36]$. In our study, the statistical analysis failed to confirm an association between these invasive procedures (CVC, urinary catheter) and mortality. The reason may be that $91.5 \%$ of the patients in our study continuously had a central venous catheter ( $95 \%$ for urinary catheter) in the ICU, making the groups of patients without a central catheter or without a urinary catheter too small for comparison. A previous study showed that catheter removal could reduce the incidence of candidemia. Therefore, if these catheters are suspected to be the source of candidemia, we should try to decrease the utilization of these invasive devices and remove these catheters as early as possible $[14,37]$. In our study, $32.9 \%$ of patients received empirical antifungal therapy, which was similar to the result of a previous study. Current guidelines recommend empiric antifungal therapy; however, this often fails to provide any benefit to ICU patients and may result in significant overtreatment [16].

The limitations of this study must be acknowledged. This was a single-center retrospective study, so the results may not be generalizable to all patients with candidemia. The epidemiological findings in our institution will pave the way for more in-depth studies and help us establish better antifungal stewardship in our hospital.

\section{Conclusion}

C. albicans was the most frequently isolated fungal species. Most isolates were susceptible to the antifungal agents. The worst GCS score, P/F ratio, and MAP within three days after admission were independent risk factors for mortality due to candidemia among critically ill patients. Further multicenter studies in different geographical regions on candidemia in critically ill patients should be conducted to help intensive care specialists assess the distribution and trends in their patients with suspected fungal infections.

\section{Abbreviations}

BSI: Bloodstream infection; CLSI: Clinical and laboratory standards; COPD: Chronic obstructive pulmonary disease; CVC: Central venous catheter; GCS: Glasgow Coma Scale; IC: Invasive candidiasis; ICU: Intensive care unit; MAP: Mean arterial pressure; $\mathrm{P} / \mathrm{F}$ ratio: $\mathrm{PaO}_{2} / \mathrm{FiO}_{2}$ ratio; SOFA: Sequential Organ Failure Assessment

\section{Acknowledgments}

We thank all the infection control doctors and nurses in the Department of Infection Control, Peking University People's Hospital. There was no funding received for this research.

\section{Funding}

None.

Availability of data and materials

The data set supporting the conclusions in this article is available from the corresponding author on reasonable request.

\section{Authors' contributions}

ZX, FZ and QW participated in data collection and interpretation. YA and ZX participated in the study design, analysis of data, and writing of the manuscript. All authors read and approved the final manuscript.

Ethics approval and consent to participate

Not applicable.

\section{Consent for publication}

Not applicable.

\section{Competing interests}

The authors declare that they have no competing interests.

\section{Publisher's Note}

Springer Nature remains neutral with regard to jurisdictional claims in published maps and institutional affiliations.

Received: 20 January 2019 Accepted: 1 May 2019

Published online: 29 May 2019

\section{References}

1. Pappas PG, Lionakis MS, Arendrup MC, Ostrosky-Zeichner L, Kullberg BJ. Invasive candidiasis. Nat Rev Dis Primers. 2018:4:18026.

2. Bassetti M, Merelli M, Righi E, Diaz-Martin A, Rosello EM, Luzzati R, et al. Epidemiology, species distribution, antifungal susceptibility, and outcome of Candidemia across five sites in Italy and Spain. J Clin Microbiol. 2013;51: 4167-72.

3. Lai CC, Tan CK, Huang YT, Shao PL, Hsueh PR. Current challenges in the management of invasive fungal infections. J Infect Chemother. 2008;14:77-85.

4. Bartoletti M, Giannella M, Lewis R, Caraceni P, Tedeschi S, Paul M, et al. A prospective multicentre study of the epidemiology and outcomes of bloodstream infection in cirrhotic patients. Clin Microbiol Infect. 2018;24:541-6.

5. Yapar N. Epidemiology and risk factors for invasive candidiasis. Ther Clin Risk Manag. 2014;10:95-105.

6. Martin-Loeches I, Perner A. Focus on infection and sepsis in intensive care patients. Intensive Care Med. 2016;42:491-3.

7. Yang Y, Guo F, Kang Y, Zang B, Cui W, Qin B, et al. Epidemiology, clinical characteristics, and risk factors for mortality of early- and late-onset invasive 
candidiasis in intensive care units in China. Medicine (Baltimore). 2017:96:e7830

8. Blumberg HM, Jarvis WR, Soucie JM, Edwards JE, Patterson JE, Pfaller MA, et al. Risk factors for candidal bloodstream infections in surgical intensive care unit patients: the NEMIS prospective multicenter study. The National Epidemiology of mycosis survey. Clin Infect Dis. 2001;33:177-86.

9. Liu W, Lai C, Li M, Wu C, Ko W, Hung Y, et al. Clinical manifestations of candidemia caused by uncommon Candida species and antifungal susceptibility of the isolates in a regional hospital in Taiwan, 2007-2014. J Microbiol Immunol Infect. 2017:30183-8.

10. Tadec L, Talarmin J, Gastinne T, Bretonnière C, Miegeville M, Le Pape P, Morio F. Epidemiology, risk factor, species distribution, antifungal resistance and outcome of Candidemia at a single French hospital: a 7-year study. Mycoses. 2016;59:296-303.

11. Pfaller MA, Andes DR, Diekema DJ, Horn DL, Reboli AC, Rotstein C, et al. Epidemiology and outcomes of invasive candidiasis due to non-albicans species of Candida in 2,496 patients: data from the prospective antifungal therapy (PATH) registry 2004-2008. PLoS One. 2014;9:e101510.

12. Sipsas NV, Lewis RE, Tarrand J, Hachem R, Rolston KV, Raad II, Kontoyiannis DP. Candidemia in patients with hematologic malignancies in the era of new antifungal agents (2001-2007): stable incidence but changing epidemiology of a still frequently lethal infection. Cancer-Am Cancer Soc. 2009;115:4745-52

13. Marchetti O, Bille J, Fluckiger U, Eggimann P, Ruef C, Garbino J, et al. Epidemiology of candidemia in Swiss tertiary care hospitals: secular trends, 1991-2000. Clin Infect Dis. 2004;38:311-20.

14. Azoulay E, Dupont H, Tabah A, Lortholary O, Stahl JP, Francais A, et al. Systemic antifungal therapy in critically ill patients without invasive fungal infection*. Crit Care Med. 2012;40:813-22.

15. Cortegiani A, Russotto V, Maggiore A, Attanasio M, Naro AR, Raineri SM, Giarratano A. Antifungal agents for preventing fungal infections in nonneutropenic critically ill patients. Cochrane Database Syst Rev. 2016;D4920.

16. Bailly S, Bouadma L, Azoulay E, Orgeas MG, Adrie C, Souweine B, et al. Failure of empirical systemic antifungal therapy in mechanically ventilated critically ill patients. Am J Respir Crit Care Med. 2015;191:1139-46.

17. Kriengkauykiat J, Ito Jl, Dadwal SS. Epidemiology and treatment approaches in management of invasive fungal infections. Clin Epidemiol. 2011;3:175-91.

18. Hospenthal DRMC. Persistence of pigment production by yeast isolates grown on CHROMagar Candida medium. J Clin Microbiol. 2002;12:4768-70.

19. Tseng $T Y$, Chen $T C, H_{0} C M$, Lin $P C$, Chou CH, Tsai CT, et al. Clinical features, antifungal susceptibility, and outcome of Candida guilliermondii fungemia: an experience in a tertiary hospital in mid-Taiwan. J Microbiol Immunol Infect. 2018;51:552-8.

20. Yap HY, Kwok KM, Gomersall CD, Fung SC, Lam TC, Leung PN, et al. Epidemiology and outcome of Candida bloodstream infection in an intensive care unit in Hong Kong. Hong Kong Med J. 2009;15:255-61.

21. Pfaller MA, Messer SA, Moet GJ, Jones RN, Castanheira M. Candida bloodstream infections: comparison of species distribution and resistance to echinocandin and azole antifungal agents in intensive care unit (ICU) and non-ICU settings in the SENTRY antimicrobial surveillance program (2008-2009). Int J Antimicrob Agents. 2011;38:65-9.

22. Lamoth F, Lockhart SR, Berkow EL, Calandra T. Changes in the epidemiological landscape of invasive candidiasis. J Antimicrob Chemoth. 2018;73:i4-i13.

23. Hesstvedt L, Gaustad P, Andersen CT, Haarr E, Hannula R, Haukland HH, et al. Twenty-two years of candidaemia surveillance: results from a Norwegian national study. Clin Microbiol Infect. 2015;21:938-45.

24. Arendrup MC, Dzajic E, Jensen RH, Johansen HK, Kjaeldgaard P, Knudsen JD, et al. Epidemiological changes with potential implication for antifungal prescription recommendations for fungaemia: data from a nationwide fungaemia surveillance programme. Clin Microbiol Infect. 2013;19:E343-53.

25. O'Leary RA, Einav S, Leone M, Madach K, Martin C, Martin-Loeches I. Management of invasive candidiasis and candidaemia in critically ill adults: expert opinion of the European Society of Anaesthesia Intensive Care Scientific Subcommittee. J Hosp Infect. 2018:98:382-90.

26. Kalantar EAMH. Candida non albicans isolates with a high antibiotic resistance: a real threat for cancer patients in Karaj City. Antimicrob Resist Infect Control. 2015;(Suppl 1):170.

27. Pu S, Niu S, Zhang C, Xu X, Qin M, Huang S, Zhang L. Epidemiology, antifungal susceptibilities, and risk factors for invasive candidiasis from 2011 to 2013 in a teaching hospital in Southwest China. J Microbiol Immunol Infect. 2017;50:97-103.
28. Mean M, Marchetti O, Calandra T. Bench-to-bedside review: Candida infections in the intensive care unit. Crit Care. 2008;12:204.

29. Kett DH, Azoulay E, Echeverria PM, Vincent JL. Candida bloodstream infections in intensive care units: analysis of the extended prevalence of infection in intensive care unit study. Crit Care Med. 2011;39:665-70.

30. Falagas ME, Roussos N, Vardakas KZ. Relative frequency of albicans and the various non-albicans Candida spp among candidemia isolates from inpatients in various parts of the world: a systematic review. Int J Infect Dis. 2010;14:e954-66.

31. Horn DL, Neofytos D, Anaissie EJ, Fishman JA, Steinbach WJ, Olyaei AJ, et al. Epidemiology and outcomes of candidemia in 2019 patients: data from the prospective antifungal therapy alliance registry. Clin Infect Dis. 2009;48: 1695-703.

32. Viudes A, Peman J, Canton E, Ubeda P, Lopez-Ribot JL, Gobernado M. Candidemia at a tertiary-care hospital: epidemiology, treatment, clinical outcome and risk factors for death. Eur J Clin Microbiol Infect Dis. 2002 21:767-74.

33. Cheng Y, Lin L, Young T, Liu C, Chen C, Tsay R. Risk factors for candidemiarelated mortality at a medical center in Central Taiwan. J Microbiol Immunol Infect. 2006:39:155.

34. Guo F, Yang Y, Kang Y, Zang B, Cui W, Qin B, et al. Invasive candidiasis in intensive care units in China: a multicentre prospective observational study. J Antimicrob Chemoth. 2013;68:1660-8.

35. Li D, Xia R, Zhang Q, Bai C, Li Z, Zhang P. Evaluation of candidemia in epidemiology and risk factors among cancer patients in a cancer center of China: an 8-year case-control study. BMC Infect Dis. 2017;17.

36. Toma LSSFF. Risk factors for lung colonization byCandida albicansin a general ICU. Crit Care. 2008;12.

37. Pappas PG, Kauffman CA, Andes DR, Clancy CJ, Marr KA, Ostrosky-Zeichner L, et al. Clinical practice guideline for the Management of Candidiasis: 2016 update by the Infectious Diseases Society of America. Clin Infect Dis. 2016; 62:e1-e50.
Ready to submit your research? Choose BMC and benefit from:

- fast, convenient online submission

- thorough peer review by experienced researchers in your field

- rapid publication on acceptance

- support for research data, including large and complex data types

- gold Open Access which fosters wider collaboration and increased citations

- maximum visibility for your research: over $100 \mathrm{M}$ website views per year

At BMC, research is always in progress.

Learn more biomedcentral.com/submissions 